\title{
An active avoidance task utilizing ice water as the unconditioned stimulus
}

\author{
CLYDE C. HEPPNER and ERNEST D. KEMBLE \\ University of Minnesota, Morris, Minnesota
}

\begin{abstract}
A one-way active avoidance task for rats utilizing an ice-water unconditioned stimulus is described. The apparatus and procedures are similar to those a commonly used shock-avoidance task. Ice-water avoidance seems to be quite sensitive to age differences in rats. The procedure may also be useful in studies of conspecific aggression.
\end{abstract}

Although the aversive properties of ice water seem to parallel those of electric shock in a number of ways (e.g., Myer, 1971), some recent studies have shown distinct differences between ice-water and shock-motivated passive avoidance in the effect of septal lesions (Caplan, 1973; Frank \& Beatty, 1974) and in the comparison of wild and domesticated rats (Hughes, 1976). In view of these differences, and of the suggestion that ice water is a more "ecologically normal" aversive agent (Thompson \& Galosy, 1969), it seemed of interest to develop an ice-water-motivated active avoidance task similar to a commonly used shock-motivated procedure. This article describes such a task.

\section{APPARATUS}

The apparatus is a modified Lafayette automated avoidance system (Model 85250). It was possible to adapt this apparatus by substituting a $24 \times 17.5 \times 20 \mathrm{~cm} \mathrm{ex}-$ perimental chamber with a flat black trapdoor for the original $21 \times 21.5 \times 23.5 \mathrm{~cm}$ experimental chamber with grid floor. The stainless steel end wall containing a $9 \times$ $20 \mathrm{~cm}$ retractable wall concealing a $12 \times 17.5 \mathrm{~cm}$ stainless steel avoidance platform $10 \mathrm{~cm}$ above the floor was unaltered. Thus, aside from a slight increase in the size and change in flooring of the experimental chamber, the apparatus was quite similar in dimensions, nature of the conditioned stimulus (CS), and response requirements. The trapdoor floor was supported by a solenoid-operated trip lever connected to a Lafayette (Model 85250) avoidance system programmer. When tripped, the trapdoor opened, revealing a white Plexiglas chamber $(24 \times$ $17.5 \times 40 \mathrm{~cm})$ containing $26-28 \mathrm{~cm}$ of ice water. A 75-W projection lamp (Anchor Optical Co.), delivering 140-lx illumination (floor level), was mounted on the side wall $0.25 \mathrm{~cm}$ above the floor of the avoidance platform. Extraneous sound was masked by white noise delivered by a $5.0-\mathrm{cm}$-diam speaker mounted $10 \mathrm{~cm}$ above the

The authors' mailing address is: Division of Social Sciences, University of Minnesota, Morris, Minnesota 56267. avoidance platform. Trials were programmed and latencies recorded by the avoidance systems programmer. Following immersion, the rats were warmed in a $20 \times 32$ $\times 31 \mathrm{~cm}$ aquarium containing clay litter by an infrared lamp.

\section{PROCEDURES}

All rats were initially habituated to the experimental chamber for two 10 -min trials conducted $12.5 \mathrm{~h}$ apart. On the 2nd day, the subject was placed in the chamber, and $5 \mathrm{sec}$ later the retractable wall opened (CS). The subject was allowed up to $10 \mathrm{sec}$ to leap onto the avoidance platform [conditioned response (CR)]. Following a CR, the subject was allowed to remain on the avoidance platform for $5 \mathrm{sec}$, and then was gently pushed back into the experimental chamber by the retractable wall and returned to its home cage. If a CR did not occur, the trapdoor opened, plunging the subject into the ice water. The subject was promptly retrieved from the ice water (2.9$10.6 \mathrm{sec}$, mean $=6.4 \mathrm{sec}$ ), dried in a cotton towel, placed into the warming chamber for 2-3 $\mathrm{min}$, and then returned to its home cage. The subjects received two training trials per day, $12.5 \mathrm{~h}$ apart.

\section{RESULTS}

Preliminary testing of the apparatus was conducted with six mature (180-200-day-old) Holtzman rats. Each rat received 20 acquisition trials (testing was terminated at this time, due to illness of the experimenter). The performance of these rats improved steadily, with 5 of 6 rats achieving $60 \%$ or more avoidances on Trials $16-20$ (mean $=67 \%$ ). Thus, mature rats can acquire this response with reasonable speed (although apparently slightly less rapidly than they do its shock-motivated counterpart). A second experiment was conducted with 18 younger (70-90-dayold) Holtzman rats. These rats experienced considerable difficulty with the task. The rats achieved only $31 \%$ avoidance on Trials 16-20, and only 9 of 18 rats achieved $80 \%$ or more avoidance by Trials $66-70$. Comparison of 
the avoidance performance of the older (mean $=67 \%$ ) and younger (mean $=31 \%$ ) rats on Trials $16-20$ revealed significantly more avoidances by older rats $[\mathrm{t}(23)=2.21$, $\mathrm{p}<.05]$. Since other investigators have reported superior performance of older rats in conditioned emotional response (CER) (Harrison, Westbrook, \& Pavlik, 1984) and conditioned taste aversion (Guanowsky, Misanin, \& Ricco, 1983), this task may prove useful for investigations of age-related changes in learning. Informal observations during our second experiment also suggested that after several immersions in ice water, the agonistic behavior of the rats toward both the experimenter and conspecifics increased considerably. This behavior consisted of both offensive and defensive postures and thus may be a useful alternative to footshock-elicited aggression, which primarily produces defensive components. We believe that this technique may offer a useful alternative to shockmotivated active avoidance.

\section{REFERENCES}

Caplan, M. (1973). An analysis of the effects of septal lesions on negatively reinforced behavior. Behavioral Biology, 9, 129-167.

Frank, L. H., \& BeatTy, W. W. (1974). Effects of septal lesions on passive avoidance behaviors using ice water as the aversive stimulus. Physiology \& Behavior, 12, 321-323.

Guanowsky, V., Misanin, J. R., \& Ricco, D. C. (1983). Retention of conditioned taste aversion in weanling, adult, and old-age rats. $B e-$ havioral and Neural Biology, 37, 173-178.

Harrison, D. W., Westbrook, R. D., \& Pavlik, W. B. (1984). CER acquisition and extinction in younger and older rats. Bulletin of the Psychonomic Society, 22, 217-220.

HugHEs, C. W. (1976). Shock vs. ice-water passive avoidance learning in wild and domestic Rattus norvegicus. Animal Learning \& Behavior, 4, 66-70.

MYER, J. S. (1971). Some effects of noncontingent aversive stimulation. In F. Robert Brush (Ed.), Aversive conditioning and learning (pp. 469-528). New York: Academic Press.

Thompson, R. W., \& Galosy, R. A. (1969). A one-trial nonshock passive avoidance task for rats. Behavior Research Methods \& Instrumentation, 1, 227. 